\title{
EDUCAÇÃO, ÉTICA E ATUAÇÃO DE PROFESSORES DA INFÂNCIA: Vivências e Experiências em tempos de pandemia
}

\author{
EDUCATION, ETHICS AND PERFORMANCE OF TEACHERS IN THE INFANCIA: \\ Experiences and Experiences in times of pandemic
}

Sandra Regina Mantovani Leite $^{1}$
Zuleika Aparecida Claro Piassa $^{2}$
Jacqueline Oliveira Jovanovich $^{3}$

http://dx.doi.org/10.52641/cadcaj.v6i4.531

\begin{abstract}
RESUMO: O artigo buscará discutir o valor da dimensão ética na atuação do Professor da Infância. Nas Instituições de Educação Infantil, a organização do trabalho pedagógico se torna uma atividade que supõe interações e também se constitui como artefato cultural para que o professor tenha como foco principal a educação humanizadora da criança. As interações e brincadeiras, eixos estruturantes do trabalho pedagógico, se apresentam como uma das maiores dificuldades. Buscando refletir e organizar a prática pedagógica realizada com as crianças, especificamente neste momento desafiante de Pandemia, e, com o objetivo de compartilhar vivências e experiências, apresentaremos pistas para proporcionar novas maneiras de entender e trabalhar com a pluralidade da formação humana. Metodologicamente, este texto pauta-se em uma perspectiva crítica, utilizando-se de autores como Severino (2010 e 2015), Barradas e Tiriba (1993) e Carvalho (2016), dentre outros. Em um primeiro momento discorre sobre a relação entre a Instituição de Educação Infantil, sua humanização e a dimensão ética que perpassa sua formação e em um segundo momento relata experiências que demonstram as possibilidades de trabalho pedagógico crítico e humanizador com crianças até cinco anos de idade.
\end{abstract}

Palavras-chaves: Formação de Professores, Educação Infantil, humanização e emancipação.

ABSTRACT: The article will seek to discuss the value of the ethical dimension in the work of the Professor of Childhood. In Early Childhood Education Institutions, the organization of pedagogical work becomes an activity that supposes interactions and also constitutes a cultural artifact for the teacher to have the humanizing education of the child as the main focus. Interactions and games, structural axes of pedagogical work, present themselves as one of the greatest difficulties. Seeking to reflect and organize the pedagogical practice carried out with the children, specifically in this challenging moment of Pandemic, and, with the aim of sharing experiences and experiences, we will present clues to provide new ways of understanding and working with the plurality of human formation. Methodologically, this text is based on a critical perspective, using authors such as Severino (2010 and 2015), Barradas and Tiriba (1993) and

${ }^{1}$ Pós Doutora em Educação pela Universidade Estadual Paulista - UNESP. Docente do Departamento de Educação da Universidade Estadual de Londrina - UEL.

2 Doutora em Filosofia da Educação pela Universidade Estadual Paulista - UNESP. Docente do Departamento de Educação da Universidade Estadual de Londrina - UEL.

3 Mestranda em Educação pela Universidade Estadual de Londrina - UEL. Docente na Educação Infantil na Prefeitura Municipal de Londrina. 
Carvalho (2016), among others. At first, it discusses the relationship between the Early Childhood Institution, its humanization and the ethical dimension that permeates its formation and in a second moment it reports experiences that demonstrate the possibilities of critical and humanizing pedagogical work with children up to five years of age.

Key-words: Teacher Training, Early Childhood Education, Humanization and emancipation

\title{
1. INTRODUÇÃO
}

\author{
A barreira bierárquica pode ser superada, \\ se os professores e alunos tiverem o ato corajoso \\ de circular, de "voar" no terreno um do outro, \\ de recriar uma espécie de sociedade, de comunidade, \\ sem demagogias e hipocrisias. \\ (CARVALHO, 2016, p. 149)
}

Refletir, avaliar e buscar novas perspectivas para o momento atual é desafiador. Desafiador, porque estamos em uma sociedade que valoriza o desempenho, acima do humano. Desafiador porque o mundo precisou aprender, por meio da Pandemia do Coronavírus - Covid 19, com o Distanciamento Social, que, o outro, é-nos tão importante e tão necessário. A Sociedade do Desempenho, apresentada por Silva (2020), entendida como uma nova forma de governo da vida, atribui ao indivíduo, entre as várias cobranças já impostas pelo mundo do trabalho, novas formas de relacionamento social, em que a docilidade do espírito precisa se manifestar na positividade, como uma espécie de disposição psicológica de dizer "sim", permanentemente, aos arranjos impostos pelo capital.

A Sociedade do Desempenho tem imperado em todas as relações sociais. Com a educação não é diferente, principalmente nestes tempos de Pandemia, em que vivemos à mercê da Tecnologia: como forma de substituir as aulas presenciais, vários termos foram assumidos para esse "novo" atendimento ao ensino, como ensino remoto, ensino on-line, educação a distância, entre outros. Mas, em se tratando de crianças com a faixa etária entre 0 a 5 anos, que frequentam a Educação Infantil, em que a interação com o outro, a socialização e o afeto são alguns dos principais eixos do desenvolvimento, a ausência das aulas presenciais forçam uma nova forma de relacionamento.

Para esta nova realidade, com o 'novo normal', as interações se apresentam como uma das maiores dificuldades. Subitamente, as aulas remotas passam a ser a nova realidade na rotina das crianças pequenas, e imediatamente várias questões podem ser levantadas sobre essa novidade "forçada" de ensino. Em especial, para essa faixa etária, o primeiro questionamento que 
surge é: todas as crianças terão condições de acesso a essas aulas? Crianças de 6 meses a 5 anos ficariam parados em frente a uma tela ouvindo o professor? Considerando a faixa etária da Educação Infantil, as Diretrizes Curriculares Nacionais para a Educação Infantil (DCNEIBRASIL, 2012) e a Base Nacional Comum Curricular (BNCC- BRASIL, 2018), destaca que o desenvolvimento das crianças se dá pelas interações e brincadeiras, pode-se garantir que as aulas remotas estão promovendo esses eixos?

Com relação aos professores, independente do nível de ensino, sempre enfrentaram, durante toda sua história, a falta de respeito e a falta de valorização, e nestes tempos atuais houve uma reaprendizagem, um reinventar, buscando se adaptar à nova realidade da educação. Professores que há anos faziam suas aulas com raros recursos tecnológicos, passaram neste novo normal a ter que abraçar as tecnologias para poder dar continuidade ao seu trabalho. Esta situação está atrelada ao home-office, cuidados com os filhos, com os trabalhos domésticos, além de uma carga psicológica de medo, ansiedade, excesso de cobrança, planilhas e mais planilhas para serem preenchidas. Alguns aspectos precisam ser levados em consideração: com essa nova realidade e todas as mudanças que aconteceram na vida das pessoas e da educação, como está a saúde mental desses professores? As instituições têm olhado para o professor como um ser humano que também precisa de cuidados e não apenas de cobranças?

Nesse sentido, procuraremos desenvolver este artigo, partindo dessa realidade e desses questionamentos, em que trabalhadores e crianças vivem sob o estigma da racionalidade estruturante do desempenho e da submissão ao tempo, seguido pela lógica do trabalho flexível, uma análise sobre as vivências e experiências que as crianças e seus professores estão passando com o distanciamento social, também faremos a relação deste momento com a Dimensão Ética, apresentada como articuladora no processo de organização do trabalho pedagógico na Educação Infantil. Procurando ampliar o nosso arcabouço de vivências necessárias para o processo de desenvolvimento e aprendizagem da criança, partiremos de atividades que foram realizadas antes mesmo da pandemia, mas que podem ter aplicabilidade nesta situação excepcional, demonstrando assim que, os professores deram continuidade ao trabalho formativo, mas contando agora com a contribuição das famílias. E sempre estão refletindo e buscando alternativas para possibilitar aos envolvidos no processo uma educação a favor da humanização da criança. É preciso pensar em como fazer diferente, refletir a partir do que temos para alcançar formas inovadoras de atender às necessidades infantis.

O entendimento de criança que permeia este estudo é de um sujeito ativo, vislumbrado pelas teorias críticas da educação, que ao se relacionar com os outros, em busca de novas intervenções e conhecimentos, vai constituindo a sua humanidade, e esta percepção traz um novo 
paradigma para a formação e atuação de Professores na Educação Infantil, como também para as Instituições de Educação Infantil. Uma práxis emancipadora em uma Instituição de Educação Infantil preocupada com a qualidade nas interações estabelecidas e que privilegie várias dimensões no desenvolvimento infantil: epistemológica, psicológica, ética e estética.

Essas dimensões precisam ser pensadas e trabalhadas pelo professor da infância na organização do seu trabalho pedagógico, na elaboração de projetos que contemplem a criança como sujeito produtor de cultura. O Pedagogo, professor da Educação Infantil, ao priorizar na sua atuação a busca por uma educação de qualidade, em que a relação entre os envolvidos (professor e criança) tenha o diálogo, o afeto, o cuidado e o acolhimento, fortalece um trabalho que tem como base principal uma educação humanizadora.

Nesse sentido, o professor de Educação Infantil precisa se reconhecer como partícipe da sociedade, ético e político, que compreende as especificidades do seu trabalho, e reconhece sua importância na vida e na formação das crianças. A profissionalidade deste educador está na "efetivação de um cuidar que promova a educação, e de uma educação que não deixe de cuidar da criança, de atendê-la em suas necessidades e exigências essenciais desde a sua mais tenra idade" (ANGOT'TI, 2008, p.19).

Além destes pontos, é preciso ressaltar que neste texto evidenciaremos a Instituição de Educação Infantil, como espaço público, para que o professor atue com vistas a propiciar a humanização da criança. Ressaltamos que apresentaremos a relação dialética entre todos os envolvidos no processo pedagógico e buscaremos demonstrar por meio das vivências apresentadas a importância da tríade educar, cuidar e acolher como forma de atuação necessária para alcançar uma educação de qualidade.

\section{PRÁXIS PEDAGÓGICA E A RELAÇÃO ENTRE EDUCAÇÃO E ÉTICA}

E se a escola é tão importante na vida de toda criança, ela o é, inicialmente, por isso: porque ao encontrar-se com seus amigos a criança encontra neles, nesses seus amigos, os seus comuns amigos-do-saber, e, enquanto forma, encontra em tudo isso a amizade como um princípio,

uma arché, o primeiro fulgor de uma nascente vontade de saber. (CARVALHO, 2016, p. 147) 
A prática educativa (práxis) ${ }^{4}$ da instituição escolar se fundamenta principalmente no conhecimento científico. Assim, é necessário entender que este conhecimento que vem sendo produzido e reproduzido, transformado e reconfigurado surge de necessidades concretas das pessoas e de problemas que enfrentam em sua prática social. Na Educação Infantil, no entanto, este conhecimento científico divide espaço com outros saberes e práticas necessárias ao desenvolvimento saudável e pleno da criança.

A organização do trabalho pedagógico pelo professor de Educação Infantil vislumbra atender as especificidades apresentadas pela criança em formação, potencializando as experiências vivenciadas, com intencionalidade e conhecimento teórico e metodológico, articulado com a dimensão ética necessária para o acolhimento e cuidado.

Essa dimensão se torna fundamental na medida em que, a partir dela, os professores e a instituição de educação infantil colocam a criança, seu bem estar, sua condição de cidadã de direitos, suas necessidades de desenvolvimento saudável em primeiro lugar, servindo como um critério pétreo para qualquer escolha.

Quando pensamos na qualidade do que é produzido na Instituição Escolar precisamos considerar o currículo que deve levar o ser humano a construir sua humanidade, a partir de uma democratização do conhecimento historicamente elaborado. Nesse sentido, é na sala de aula que os sujeitos se encontram para, a partir de suas convicções, de suas histórias de vida e de seus valores estabelecerem interações significativas para o desenvolvimento infantil. É a vida do homem e suas experiências, é sua vida cotidiana o ponto de partida e de chegada de toda atividade e conhecimento.

Uma aula, por exemplo, não se reduz apenas a objetivos instrucionais e à assimilação consciente de conteúdos por parte do aluno, mas se refere também a aspectos afetivos, socioculturais e comunicacionais que vinculam os personagens e sujeitos ali existentes. (CARVALHO, 2016, p. 138).

O que nos importa nessa citação, como estamos tratando da formação e atuação com crianças de 0 a 5 anos, são as características relacionadas aos aspectos afetivos e culturais, ou seja, aquilo que se relaciona com as interações e brincadeiras, os dois eixos citados e referenciados nas Diretrizes Curriculares Nacionais para a Educação Infantil (BRASIL, 2012) e na Base Nacional Comum Curricular para a Educação Infantil (BRASIL, 2018). Ressaltamos que a dimensão ética se apresenta como uma articulação de todos os conceitos, eixos, atividades necessárias à formação da criança, relacionada com a realidade mais próxima. Realidade esta que

\footnotetext{
${ }^{4}$ Práxis palavra grega que significa a ação na qual o agente, o ato realizado por ele e a finalidade do ato são idênticos. (CARVALHO, A.B., 2013).
} 
implica a relação dialética entre a instituição de educação infantil e a sociedade, e que tornará mais significativo os conhecimentos para a instrumentalização dos envolvidos com vistas a lidar com a prática vivenciada. Esta relação, articulada e comprometida com as várias dimensões que formam o ser humano é que promove a verdadeira qualidade da instituição escolar, esta é a função precípua da escola, da educação em busca da elevação do ser humano.

Nessa direção, a qualidade do ato educativo está em concretizar efetivamente o processo de transmissão-assimilação do saber elaborado, inserindo de forma ativa os seres humanos para pertencimento e transformação da cultura existente. A Humanidade depende da relação existente entre os indivíduos e os grupos aos quais pertencem para viver e se reproduzir enquanto tal. Como seria possível viver sem conviver? O homem não está sozinho e está em condição de permanente devir e, portanto, nunca está pronto e acabado, nem como indivíduo e nem como espécie humana. Dessa forma, é que salientamos a importância da vida vivenciada e partilhada por crianças e professores envolvidos na dinâmica e no processo de aprender.

É preciso viver valorizando a dignidade humana. Principalmente, neste momento em que buscamos alternativas para um mundo de isolamento e distanciamento social, reconhecer as crianças e sua dignidade, para que possamos renascer, buscar a fraternidade, o diálogo, o entendimento de que o outro é importante e necessário para a própria constituição da pessoa. Os professores e as crianças precisam sonhar e tornar a vida uma bela aventura, uma convivência em que possamos nos sentir apoiados em que cada envolvido, professor, família, criança sejam encorajados a olhar para frente.

Dessa forma, Severino (2015), explica-nos a diferença entre os seres humanos e os outros animais. Diferente dos outros animais, a reprodução da humanidade supõe não somente a memória genética, mas também a memória cultural que se atualiza em cada novo membro que chega à sociedade. À medida que a humanidade foi se tornando mais complexa, esta atualização histórico-cultural também foi se complexificando, necessitando a criação de agências especializadas em realizar esta tarefa com grande número de indivíduos ao mesmo tempo. A educação se formaliza, se institucionaliza, passa a necessitar de profissionais especificamente preparados para tal intento.

A formalização cada vez maior da interação educativa decorre da própria natureza da atividade humana, que é sempre atividade intencionalmente planejada, sempre vinculada a um telos que a direciona. [...] Falar de fundamentos éticos e políticos da educação pressupõe assumi-la na sua condição de prática humana de caráter interventivo, ou seja, prática marcada por uma intenção interventiva, intencionando mudar situações individuais ou sociais previamente dadas. Implica uma eficácia construtiva e realiza-se numa necessária historicidade e num contexto social; (SEVERINO, 2015, p 2). 
Vê-se, portanto, que a ética, enquanto a reflexão e a definição da intencionalidade formativa, assume uma atitude, uma prática, que é, portanto, política, uma vez que exigirá um posicionamento frente ao indivíduo no sentido de intervir para que ele tenha uma formação voltada ao consentimento ou à mudança de suas condições sociais previamente dadas. A intencionalidade formativa junto às crianças precisa se promover a partir do diálogo. Dialogar no sentido de se esforçar por entender o outro que está conosco nesta caminhada do aprender, significa procurar pontos de contato, aproximar-se, olhar-se, empatizar-se para nos enriquecer cultural e simultaneamente. A relação entre o processo Educativo e a Ética na construção da democracia é fundamental para que possamos nos sensibilizar com os problemas que acometem a humanidade. Segundo Severino:

desenvolver ao máximo sua racionalidade filosófica, em sua tríplice dimensão: epistêmica, ética e estética, buscando delinear os telos da educação com sensibilidade profunda à condição humana. Sentir a razão de ser da existência e a pulsação da vida. Desenvolver ao máximo sua compreensão política, levando os educandos à apreensão do significado de sua inserção social e fornecendo referências para sua atuação no seio da sociedade. (SEVERINO, 2010, p. 156).

A partir dessa consideração, a educação cumpre sua função quando entendida como mediação para estabelecer-se uma cidadania crítica como horizonte teleológico. A Instituição de Educação Infantil e a Escola, em qualquer nível, precisa ser um espaço de crescimento. Um espaço em que a educação desempenhe, como nos apresenta Carvalho, uma forma democrática e humanizadora, sem ser arbitrária, “onde os educadores constroem relações mais sólidas sem serem normatizadores, podendo, junto com os alunos, construir alternativas, primeiro como reflexões e, depois, como elaborações de propostas e posturas renovadas...” (2016, p. 148).

A reflexão leva a busca de realização dos objetivos, que pressupõem que professores e crianças possam se entender como sujeitos do processo de aprendizagem, e, portanto, à medida que interagem com os outros, constroem novas formas de cultura, de moral e estabelecem um thelos que supõe a alteridade como princípio das relações humanas. Assim, a prática educativa precisa acontecer como prática transformadora e a atuação dos professores como mediadores no processo de experimentar a ética, com a sensibilidade de saber que não é possível determinar e regrar sempre; e da mesma forma as atitudes das crianças e dos envolvidos no processo de desenvolvimento e aprendizagem. As crianças e os envolvidos no processo são personagens, são seres humanos, que

como agentes que se movimentam não somente a partir, mas também em direção a novos horizontes e perspectivas que nem sempre o rigor lógico, racional e científico garante com sucesso. É preciso levar em conta a nossa 
abertura ao outro, mesmo que esse outro - as paixões, os impulsos, os sentimentos - esteja em nosso interior, provocando-nos e nos animando nessa ou naquela direção. (CARVALHO, 2013, p.168).

A Instituição de Educação Infantil, por meio de práticas reflexivas e intencionais, possibilitam a valorização do conhecimento como produção dos seres humanos históricos e em interação e a consciência das várias dimensões que compõem o processo educativo e sua contribuição para a emancipação. Por isso, é imprescindível que exista um outro que interpele, incomode e interaja provocando mudanças interiores e exteriores.

$\mathrm{Na}$ condição de mediador, o professor se torna uma espécie de pólo negativo no sentido do pensamento dialético, pois cabe-lhe desestruturar ideias pré-concebidas, conceitos estabelecidos como certezas e verdades, ou seja, promover uma relação de troca e movimento da criança como o meio e com os conhecimentos que ela já traz em suas experiências. Isso se faz pela linguagem, pelo toque e pelo olhar, pelas relações humanas afetivas que se estabelecem entre o professor e o aprendiz.

Daí que concluímos que a relação humana é prioritária no processo educativo, especialmente na Educação Infantil, na interação entre o professor e a criança que deposita confiança neste adulto que agora lhe direciona o olhar para coisas novas, ou um novo olhar para as coisas já conhecidas. Aos poucos, sua subjetividade rica em potencial vai se ampliando ainda mais neste processo de interações, caminhando para a constituição de uma personalidade autônoma, porém humanamente comprometida. "Graças à subjetividade, os homens se tornam produtores e fruidores de cultura, da qual a atividade educacional é produtora, sistematizadora e transmissora." (SEVERINO, 2001, p. 80). Pelo conhecimento teórico, por meio do processo educativo formal, que o papel de conscientizar toma forma. Sendo assim, como sujeitos que usufruem e produzem cultura, auxiliamos nas modificações necessárias para a formação de um cidadão ativo. Para o homem, do ponto de vista antropológico,

[...] a educação é um processo intrinsecamente público, pois é sua tarefa inserir, a partir de mecanismos informais ou formais, o indivíduo em seu grupo cultural e em sua pólis, de modo a torná-lo um socíola. [...] No caso da educação humana, são necessários mecanismos de aprendizagem, o que pressupõe referências significativas de sensibilização para que o indivíduo compartilhe vivências com seus semelhantes. (SEVERINO, 2001, p.79).

Para além da apropriação de conteúdos, o enriquecimento subjetivo também supõe o desenvolvimento moral da criança. A vivência moral é comum a todo ser humano e na escola se 
intensifica, pois lida-se com seres humanos diversos, com referências familiares e pessoais diversas. Os valores morais também estão presentes na ação dos professores:

ao que cada um pode observar em si mesmo e ao que se pode constatar pelas mais diversificadas formas de pesquisas científicas e de observações culturais, todos os homens dispõem de uma sensibilidade moral, mediante a qual avaliam suas ações, caracterizando-as por um índice valorativo, o que se expressa comumente ao serem consideradas como boas ou más, lícitas ou ilícitas, corretas ou incorretas. (SEVERINO, 2015, p. 4)

Ao organizar o trabalho pedagógico, tanto a ética em seu aspecto reflexivo, como a moral terão relevante papel e serão espelho da formação e atuação do professor como ser, pessoa e como profissional. A ética que se espera que a escola desenvolva é a ética que advenha da razão emancipatória ou objetiva e uma moral que tenha como motor de propulsão o próprio homem, sua existência, sua liberdade, seu caráter coletivo e interligado.

Segundo Horkheimer (2002), a razão se divide em duas dimensões, a razão instrumental ou subjetiva e a razão emancipatória ou objetiva. A razão objetiva visa a preservação da humanidade, tomando o homem como parte da natureza e em uma perspectiva universal; e a estrutura objetiva da razão, ou seja, voltada a totalidade e ao bem coletivo é que seria o determinante para as ações, pensamentos e decisões individuais. Ancora-se nos fins voltados ao bem supremo de todos os homens. A razão subjetiva, ao contrário, se aproxima daquilo que hoje chamamos de razão em uma sociedade danificada. Danificada por ter como base um progresso material que não se estendeu na mesma proporção para a subjetividade humana. Em outras palavras, avançamos na produção de bens materiais, na ciência, na tecnologia, mas regredimos em nossa humanidade, a ponto de precisar ser colocado em lei que uma criança tem direito a vida, como está explícito em nosso Estatuto da Criança e do adolescente (BRASIL, 1990).

A razão instrumental é aquela calculada em função do benefício de um grupo ou de uma pessoa, em detrimento do bem dos demais. O cultivo desta razão levou ao grande nível de progresso atingido pelo mundo, resultante de uma ação generalizada de predação da natureza e exploração do trabalho de grandes grupos humanos. Também, levou a ciência a se tornar mercadoria; e as tecnologias produzidas por ela se tornaram acessíveis somente a grupos economicamente empoderados que definem quem vai viver, quem vai sobreviver e quem vai morrer.

A pandemia, que hoje assola o mundo, desnudou esse panorama e sua crueldade, deixando transparecer ainda mais as desigualdades econômicas, o nível de regressão subjetiva em que se encontra nossa sociedade, nossos governos e o quanto a razão subjetiva ou instrumental ainda é a que controla as decisões nas várias esferas sociais, seja ela política, econômica, jurídica, 
etc. Dito de outra forma, mesmo com uma pandemia dizimando o mundo com a ameaça de morte de um grande número de pessoas, os critérios que permeiam as ações ainda são de natureza econômica e política. O ser humano, mesmo em meio a uma situação tão perversa para todos, não está sendo prioridade da própria humanidade.

Eis que a educação é chamada a continuar seu trabalho formativo, mesmo em dado contexto de perigo para a seguridade, pois segundo a lógica vigente na sociedade a vida não pode parar. Temos de nos perguntar: eticamente, vamos reforçar a razão subjetiva, instrumental ou vamos buscar, mesmo em meio às dificuldades, reverter este quadro e prezar pela razão emancipatória? Como, em práticas cotidianas e localizadas vamos reacender o debate sobre a necessidade de religarmos o homem à natureza? Como vamos retomar a ideia de que devemos zelar pelo bem coletivo pelo simples fato de ser bom para todos? Como vamos colaborar no âmbito da educação para a emancipação do homem?

Pensando em estimular a escola e os professores a refletirem sobre as possibilidades de organizar um trabalho pedagógico, pautado em uma educação humanizadora, ou seja, voltada a princípios éticos de valor supremos, com vistas ao cultivo da cidadania, e ao bem comum, que trazemos neste texto relato de experiências que não tem o objetivo de serem modelo ou receituário, ao contrário, tem o objetivo de demonstrar que é possível, mesmo em meio a uma sociedade danificada, assombrada por uma pandemia viral que não escolhe classe social, escancara a fragilidade dos mais pobres em defender sua própria vida.

\section{RELATO DE EXPERIÊNCIAS PARA UM NOVO CENÁRIO EDUCACIONAL}

"[...] Eu fui aparelhado para gostar de passarinhos. Tenho abundância de ser feliz.por isso. Meu quintal é maior do que o mundo. Sou um apanhador de desperdícios: amo os restos como as boas moscas. Queria que a minha voz tivesse um formato de canto.

Porque eu não sou da informática: eu sou da invencionática. Só uso a palavra para compor meus silêncios." (Manoel de Barros, 2015, p. 149)

Como já apresentamos no início deste artigo, o cenário mundial da Pandemia do Coronavírus trouxe para a Educação e, em específico para os envolvidos com a Educação Infantil, além de grandes desafios, novas formas de refletir e organizar a prática pedagógica realizada com as crianças. Mesmo porque, a geração atual de profissionais da educação nunca vivenciou uma realidade de pandemia, isolamento, distanciamento, quarentena. A maneira de proporcionar as atividades e o conhecimento, o espaço físico, as interações e as brincadeiras 
foram substituídos por telas de computadores, celulares e por um distanciamento social obrigatório e cruel, porém necessário. Por todas essas razões, partimos de questionamentos que indicam caminhos para as práticas vivenciadas: será que conseguimos promover o desenvolvimento da criança em tempos de distanciamento social? Como prezar por uma Ética em nossas escolhas que vise o bem comum? Conseguimos identificar e avaliar as especificidades de cada realidade? Por meio do Ensino Remoto garantimos as interações e as brincadeiras, que são os eixos estruturantes para a Educação Infantil? As atividades e experiências trabalhadas neste momento potencializam uma educação humanizadora, e voltada para o bem comum à priori, ou seja, pautadas na razão emancipatória?

Valorizar as relações, mesmo que à distância, utilizando ferramentas tecnológicas, se torna um desafio para os sistemas de ensino, para os professores e para as crianças. Ao elaborar as sequências didáticas, o professor necessita levar em consideração a saúde emocional e mental das crianças e de suas famílias, que vivem uma mistura de sentimentos advindos das experiências com o contexto vivenciado. Detalhes esses que não podem ser negligenciados, haja vista que corremos o risco de retroceder como meros transmissores de conteúdos e com materiais estereotipados. Assim como Nunes (2018) explica: "Estereótipo vem do grego stereos e typos constituindo "impressão sólida". Hoje, as definições significam todos do mesmo "tipo", parecido, igual, cópia. É o desenho que veda qualquer processo de criação e de desenvolvimento da criança". Portanto, refletir sobre as atividades e sobre os pressupostos teórico-metodológicos que sustentam a prática e o processo de aprender, buscando prezar pela humanização emancipadora, constitui uma forma de proporcionar para a criança momentos de desenvolvimento significativo, voltado à sua constituição como humano e como cidadã.

Os exemplos de atividades a seguir, contemplam a área externa, que pode ser o quintal, jardim, ou até mesmo um pequeno espaço num apartamento, que pode ser preparado para explorar a brincadeira. Optamos por experiências fora de quatro paredes, levando em consideração, também, que crianças muito pequenas foram proibidas de frequentar escolas, shoppings, mercados e até mesmo praças públicas em seus bairros. Por essa razão, muitas delas acabaram ficando tempo demais dentro de suas casas envolvidas com telas digitais, sem contato com experiências ao ar livre, outras ficaram à mercê dos meios de comunicação de massa sendo constantemente bombardeados por uma informação consumista e que visa à desinformação.

Muitos são os estudos e pesquisas, nas várias áreas de conhecimento que afirmam que o contato com a natureza aumenta a sensação de bem-estar, melhora o humor e alivia os sintomas de depressão, ansiedade e estresse. Pensando no bem estar das crianças, nesse momento tão atípico, e com o objetivo de compartilhar vivências e experiências, apresentaremos alguns 
momentos, que tem como intuito servir para a reflexão e impulsionamento de novas práticas pedagógicas. Atividades compostas de elementos simples, facilmente encontrados em casa ou na natureza. Como afirma, Santos:

[...] Sabemos que a pandemia não é cega e tem alvos privilegiados, mas mesmo assim cria-se com ela uma consciência de comunhão planetária, de algum modo democrática. A etimologia do termo pandemia diz isso mesmo: todo o povo. A tragédia é que neste caso a melhor maneira de sermos solidários uns com os outros é isolarmo-nos uns dos outros e nem sequer nos tocarmos. É uma estranha comunhão de destinos (SANTOS, 2020, p. 7).

Proteger nossas crianças nesta pandemia é o primeiro princípio ético a se considerar para a organização do trabalho pedagógico docente e a natureza, por si só, já nos apresenta infinitas possibilidades para organizar ações com os pequenos, e é perfeita para explorar todos os sentidos, permitindo que as crianças tenham novas experiências, além de trazer uma sensação de prazer, alegria e paz. Precisamos promover essas sensações. Segundo pesquisa realizada pelo Instituto de Psiquiatria do Hospital das Clínicas da Universidade de São Paulo (USP), a saúde emocional das crianças foi afetada devido ao isolamento. Alteração no sono, agressividade, desânimo, acesso de raiva, sintomas de ansiedade e depressão, são alguns sinais do que o distanciamento social trouxe para as crianças. Levando em consideração os prejuízos que a nova rotina motivada pelo Coronavírus forçou as crianças viverem, destacamos que há muito já é comprovado que crianças que passam mais tempo em contato com áreas verdes e naturais, tendem a apresentar um comportamento harmonioso, feliz, brincam e interagem melhor, além de ter uma melhor percepção do espaço em que vivem.

Observamos nas imagens que seguem: de um lado uma criança brincando num canteiro de terra, caminha sentindo a terra com os pés. Já na outra imagem, a criança sente o cheiro do alecrim, e nesses dois momentos as sensações estão sendo aguçadas: o tato, olfato, visão, audição e paladar estão se desenvolvendo. Louv (2018) ressalta que “...descobrir - ou redescobrir - a natureza pelos sentidos é apenas uma forma de aprender, de prestar atenção. E prestar atenção é mais fácil quando você está de fato fazendo alguma coisa, não apenas considerando como essa coisa pode ser feita." Dessa forma, experimentar o cheiro do alecrim, a textura da terra, leva a criança a uma experiência única, e que ficará marcada para a vida. Experiências simples, que encantam as crianças, vivências afetivas que envolvem sensações e prazer.

Figura $1 \quad$ Figura 2 


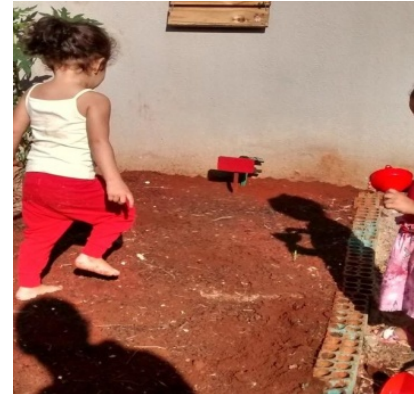

Fonte: Arquivo Pessoal

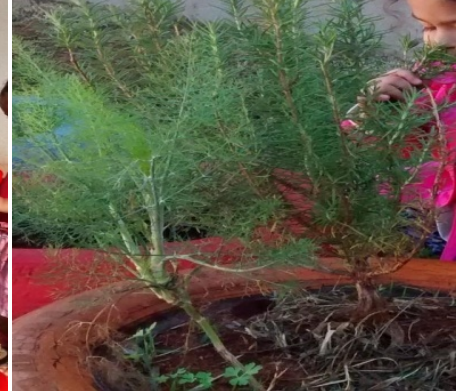

Fonte: Arquivo Pessoal

A própria Base Nacional Comum Curricular (BNCC), considera que a relação da criança com a natureza é um dos direitos de aprendizagem, garantido em vivências como conviver, brincar, participar, explorar, expressar-se e conhecer-se, e no Campo de Experiência: "Espaços, tempos, quantidades, relações e transformações”. Segundo a BNCC:

As crianças vivem inseridas em espaços e tempos de diferentes dimensões, em um mundo constituído de fenômenos naturais e socioculturais. Desde muito pequenas, elas procuram se situar em diversos espaços (rua, bairro, cidade etc.) e tempos (dia e noite; hoje, ontem e amanhã etc.). Demonstram também curiosidade sobre o mundo físico (seu próprio corpo, os fenômenos atmosféricos, os animais, as plantas, as transformações da natureza, os diferentes tipos de materiais e as possibilidades de sua manipulação etc.). (BRASIL, 2018, p.42)

Quando oferecemos às crianças o contato com a natureza, com brincadeiras ao ar livre, ampliamos as possibilidades de experimentar diversas sensações e novas descobertas, bem como estamos demonstrando que nossa relação prima pelo respeito com todas as formas de vida. Por meio da natureza vários conhecimentos são trabalhados de forma lúdica, propiciando a formação de valores tautológicos como: respeito, amor, preservação, conscientização, que em suma, constituirão a razão emancipatório deste humano em desenvolvimento.

(...) é possível, trancados entre quatro paredes, convivendo com representações da vida concreta, tal qual ela se manifesta na natureza, conhecermos em sentido pleno, a natureza, a vida? Não. Não é possível amar, respeitar, defender algo com o qual não convivemos e não estabelecemos uma relação afetiva, apenas o conhecemos intelectualmente. $\mathrm{O}$ amor, o respeito, não se aprendem simplesmente através de teorias. São sentimentos que se constroem, e se incorporam a partir da vivência física e espiritual; através de uma relação inteira de corpo/emoção/razão com o universo maior do qual somos parte". (TIRIBA, 2006, p. 9).

O trabalho com a natureza proporciona a humanização e a alteridade necessária para que a criança se sinta partícipe e sujeito do mundo, bem como se desenvolva com um olhar crítico para este mesmo mundo, reconhecendo-se como parte da natureza, que dela usufrui e com ela 
não pode estabelecer uma relação de predação como historicamente tem acontecido em todos os cantos do planeta. As crianças aprendem respeito, cuidado, autonomia, resiliência, equilíbrio, consciência, sensibilidade que são valores universais necessários à sobrevivência da própria humanidade. Segundo Oliveira e PO. Nigriello (2002, p.1) o contato com a natureza possibilita ao infante ter:

liberdade $[\ldots]$ recebe estímulos constantes e variados, trabalha e enriquece a sua percepção do espaço e desenvolve a sua sensibilidade, coordenação motora, imaginação, mente e criatividade, socializando-se, trocando experiências, criando vínculos com outras crianças e com adultos de diversas classes sociais, crenças, raças, culturas e etnias e aprende a ser solidária. (OLIVEIRA e PO. NIGRIELLO, 2002, p.1)

Sugerir para as crianças que, juntamente com os pais ou responsáveis, criem uma horta em casa, mesmo que seja em um pequeno vaso, é uma proposta interessante, pois, além de oferecer à criança o contato com elementos naturais, proporciona uma experiência com a vida. Felicidade e Liberdade, sentimentos caros ao ser humano, assumindo o valor da historicidade e da sensibilidade como motor para as realizações humanas. $\mathrm{O}$ ato de plantar, cuidar, esperar e acompanhar o crescimento da planta até a colheita possibilita à criança consciência de como funciona o processo da natureza, compreende a importância do plantio e colheita, aprende a experimentar novos alimentos, a se alimentar de forma saudável, e acima de tudo, desenvolve a consciência ecológica. É arriscando, criando, desejando, escolhendo e habitando esse mundo que os seres humanos revelam sua humanidade e experimentam a sua singularidade. Dessa forma, as crianças como infantes em busca de novas formas de viver e experenciar os prazeres da natureza e dos sentidos, se constituem como sujeitos que se familiarizam com as paixões, com os medos, com os sonhos e com novas possibilidades de fazer o mundo melhor.

Figura 3

Figura 4
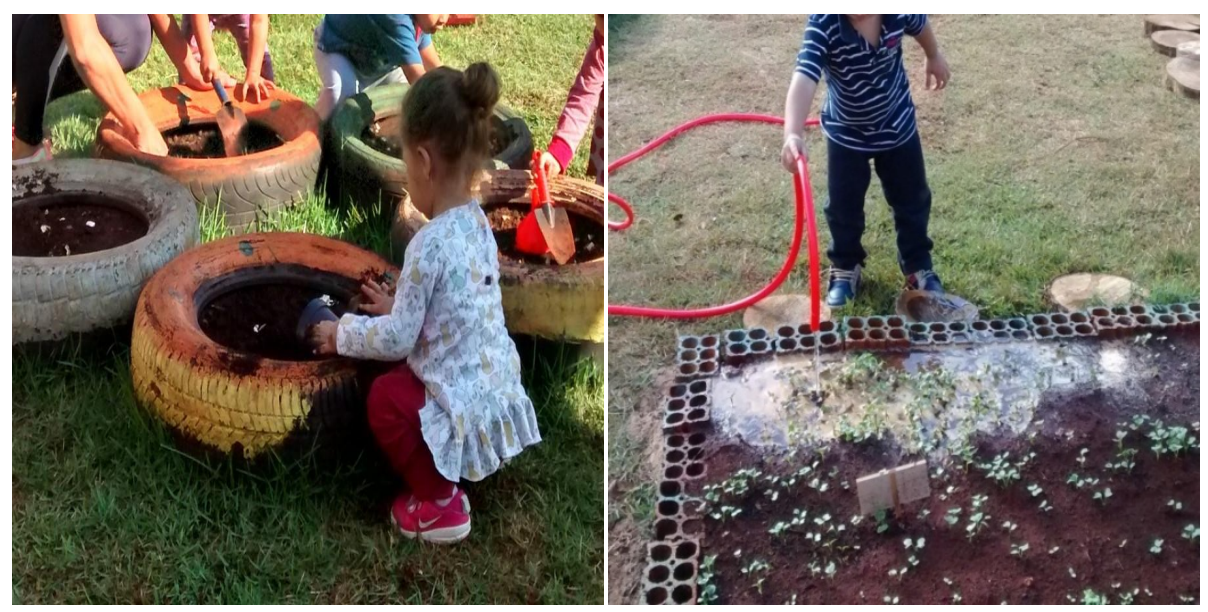

Fonte: Arquivo Pessoal

Fonte: Arquivo Pessoal 
A natureza é um laboratório vivo e nos oferece infinitas possibilidades de descobertas, como: observar o céu, os pássaros, plantas, insetos. Para as crianças e para os professores se torna um campo de pesquisa e de investigação. Inspirações e potenciais são despertados nas crianças, por meio do trabalho consciente e comprometido dos professores mediadores. Meirelles (2016) destaca a importância dessa relação:

$\mathrm{Na}$ natureza, as crianças são solicitadas a agir de dentro para fora, pois há apenas sugestões do que, como e por que fazer algo. Ao contrário dos brinquedos prontos, ou da televisão, que já possuem forma, função e conteúdo definidos, os elementos da natureza convidam a criança a agir ativamente no mundo, transformando a matéria a partir de sua imaginação e ação. Assim, de um tronco nasce um carrinho; de um sabugo, uma boneca; de uma folha de bananeira, uma cabana. Ao transformar a matéria-prima, a criança produz cultura". (MEIRELLES, 2016, p.64)

Figura 5

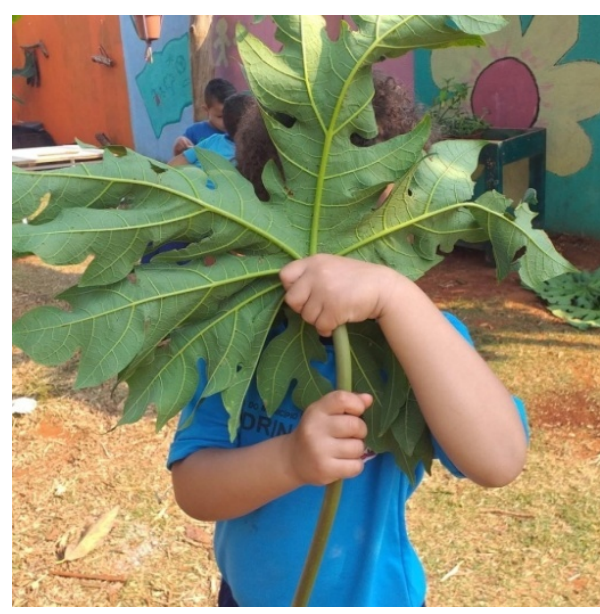

Fonte: Arquivo Pessoal
Figura 6

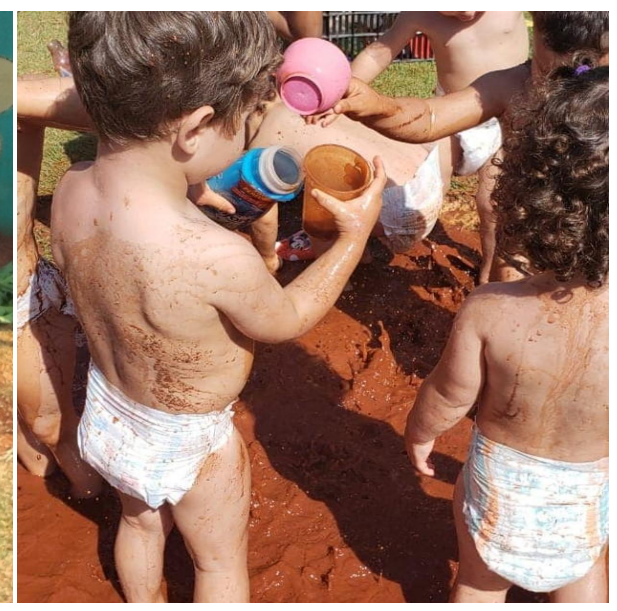

Fonte: Arquivo Pessoal

Utilizar a natureza como uma ferramenta pedagógica, brincar com e na natureza, oportuniza o desenvolvimento integral da criança. Ao trabalhar com a criança potencializando o desenvolvimento emocional, retomamos a dimensão ética como articuladora entre os vários campos de experiência.

A Dimensão Ética como articuladora entre os conhecimentos e os sentimentos que são trabalhados pelos grupos, que interagem e, portanto, assumem e possibilitam a criação de novos vínculos, "proporciona uma vida feliz, alegre e prazerosa, contribuindo para a partilha das tristezas e alegrias e criando um espírito de confiança; enfim, ela é essencial na vida das pessoas." (CARVALHO, 2016, p. 150) 
Os conceitos que compõem a razão emancipatória, passam longe de qualquer justificação empírica, no entanto, é na experiência como sujeitos históricos e sociais, mergulhados em um mundo constituído pela natureza, pela cultura e pelas pessoas em relação é que as crianças poderão se desenvolver, humanizar-se e estabelecer uma existência que beneficie toda a humanidade.

\section{CONCLUSÃO}

Ao pensarmos no mundo e na desordem que aconteceu com a sociedade por conta deste contexto pandêmico, analisamos e imprimimos a Educação a tarefa de buscar arrumar o mundo, em algum nível. Essa arrumação só se daria a contento se tomássemos a ética como uma das maneiras de desafiar o que está posto. Ao trazer esta experiência, estamos defendendo uma organização do trabalho pedagógico na Educação Infantil, pautada na Ética e alicerçada na pluralidade, assim como este texto que traz uma pluralidade de olhares. Ao valorizarmos a Dimensão Ética e a Pluralidade na atuação do professor, destacamos que o trabalho não se submete à uma visão única e unívoca da vida, das pessoas e das coisas que acontecem ao nosso redor. Como ressalta Carvalho (2016), optar por uma visão mais alargada do espaço, onde se vivem as mais variadas e desafiadoras relações humanas, faz do trabalho docente na Educação Infantil uma encantadora vivência.

$\mathrm{Na}$ base deste trabalho encontram-se além do valor à vida, outros valores que vão ao encontro de uma humanização que considere o potencial de um trabalho pedagógico voltado à emancipação, ao bem da humanidade e de seu lar, que é o planeta e sua natureza. A cidadania, a justiça social, o respeito à diversidade, aparecem para a criança como condição para que a vida aconteça.

Nesse sentido, um professor preocupado com a formação ética das crianças, de forma a contribuir para proporcionar experiências e vivências significativas, possibilitando a humanização necessária para que no futuro cultivem a democracia, a cidadania e transformem a sociedade no sentido de fazê-la mais justa e fraterna.

Os envolvidos com o processo de aprender nas Instituições de Educação Infantil e nas Instituições Familiares, partindo desse referencial teórico partem das escolhas teóricas e metodológicas utilizando-se de sua autonomia didático-pedagógica, mas também considerando sua própria condição de ser em uma sociedade danificada que precisa construir um futuro em que 
pandemias e outros males sejam combatidas de forma coletiva e voltada à vida, acima de qualquer lógica mercadológica ou status social.

\section{REFERÊNCIAS:}

ANGOTTI, Maristela (Org.). Educação infantil: para que, para quem e por quê? Campinas: Alínea, 2008.

BARROS, Manoel de. Meu quintal é maior que o mundo. Rio de Janeiro: Objetiva, p. 149, 2015.

BRASIL. Ministério da Educação. Base Nacional Comum Curricular. Brasília, 2018.

BRASIL. Ministério da Educação. Secretaria de Educação Básica. Secretaria de Educação Continuada, Alfabetização, Diversidade e Inclusão. Conselho Nacional da Educação. Diretrizes Curriculares Nacionais Gerais da Educação Básica/ Ministério da Educação. Secretária de Educação Básica. Diretoria de Currículos e Educação Integral. - Brasília: MEC, SEB, DICEI, 2013.

CARVALHO, Alonso Bezerra de. A relação professor e aluno: paixão, ética e amizade na sala de aula. Curitiba: Appris, 2016.

A sala de aula e a relação professor-aluno: paixão, ética e amizade na prática pedagógica. Tese (Livre-docência) - Faculdade de Ciências e Letras. Universidade Estadual Paulista Júlio de Mesquita Filho, Assis, 2013.

HORKHEIMER, M. Eclipse da Razão. São Paulo: Centauro Editora, 2002.

LOUV, R. A última criança na natureza - resgatando nossas crianças do transtorno de déficit de natureza. 1ed. São Paulo. Ed. Aquariana, 2018.

MEIRELLES, R. Org. Território do brincar diálogo com escolas. Territórios do brincar. 2016. Disponível em: >https://territoriodobrincar.com.br/wpcontent/uploads/2014/02/Territ\%C3\%B3rio_do_Brincar_-_Di\%C3\%A1logo_com_EscolasLivro.pdf> Acesso em: 21/03/2021. 
NUNES, Taissa Bacelar. Estereótipos nos espaços educativos: experiências nos anos iniciais a partir da cultura visual. 2018. Universidade Federal de Santa Maria, Rio Grande do Sul, 2018.

Disponível em:<https://repositorio.ufsm.br/bitstream/handle/1/15436/Nunes_Taissa_Barcelar_2018_TC C.pdf? sequence $=1$ \&is Allowed $=\mathrm{y}>$ Acesso em: 24/03/2021.

SANTOS, Boaventura de Sousa. A Cruel Pedagogia do Vírus. Coimbra: Edições Almedina, 2020, p. 7.

SEVERINO, Antonio Joaquim. Desafios da formação humana no mundo contemporâneo. Revista de Educação, Campinas, n. 29, p. 153-164, jul./dez. 2010.

Educação, sujeito e história. São Paulo: Olho d’Água, 2001.

A Filosofia e a ética na educação. 2015. Disponível em http://www2.ufpel.edu.br/fae/fepraxis/antonio-severino.pdf acesso em 20 mar 2021.

SILVA, Divino José. Sociedade de Desempenho e governo da vida deficiente. In: Educação e Filosofia, Uberlândia, v. 34, nº 70, jan./abr. 2020.

OLIVEIRA, Claudia Maria Arnhold Simões de; NIGRIELLO, Andreina. O ambiente urbano e a formação da criança. 2002. Universidade de São Paulo, São Paulo, 2002.

TIRIBA, Léa. Crianças, natureza e educação infantil. In: REUNIÃO ANUAL DA ANPEd, 29, 2006, Caxambu: Anais GT7. Disponível em<https://anped.org.br/sites/default/files/gt072304.pdf> Acesso em: 18/03/2021. 